\title{
Differential induction of LRP16 by liganded and unliganded estrogen receptor $\alpha$ in SKOV3 ovarian carcinoma cells
}

\author{
Liyuan Tian ${ }^{1, *}$, Zhiqiang $\mathrm{Wu}^{1, *}$, Yali Zhao ${ }^{1, *}$, Yuanguang Meng ${ }^{2}$, Yiling $\mathrm{Si}^{1}$, Xiaobing $\mathrm{Fu}^{1}$, \\ Yiming $\mathbf{M u}^{3}$ and Weidong $\operatorname{Han}^{1}$ \\ Departments of ${ }^{1}$ Molecular Biology, Institute of Basic Medicine, ${ }^{2}$ Obstetrics and Gynecology and ${ }^{3}$ Endocrinology, Chinese PLA General Hospital, Beijing \\ 100853, People's Republic of China \\ (Correspondence should be addressed to W Han; Email: hanwdrsw69@yahoo.com) \\ *(L Tian, Z Wu and Y Zhao contributed equally to this work)
}

\begin{abstract}
Previously, we investigated the induction effect of LRP16 expression by estrogen $\left(17 \beta\right.$-estradiol, $\left.\mathrm{E}_{2}\right)$ and established a feed-forward mechanism that activated estrogen receptor $\alpha$ $(E R \alpha)$ transactivation in estrogen-dependent epithelial cancer cells. LRP16 is required for ER $\alpha$ signaling transduction by functioning as an ER $\alpha$ coactivator. In this study, we demonstrated that LRP16 expression was upregulated in $\mathrm{E}_{2}$-responsive $\mathrm{BG}-1$ ovarian cancer cells, but was downregulated in estrogen-resistant SKOV3 ovarian cancer cells. Pure estrogen antagonist ICI 182780 did not affect LRP16 expression in SKOV3 cell. The unliganded ER $\alpha$ upregulated LRP16 expression and enhanced LRP16 promoter activity in SKOV3 cells; however, this induction was blocked by estrogen stimulation. Results from chromatin
\end{abstract}

immunoprecipitation experiment revealed a strong recruitment of the unliganded ER $\alpha$ at LRP16 promoter in the absence of estrogen; however, ER $\alpha$ was largely released from the DNA upon $E_{2}$ stimulation. Modulation in LRP16 expression level did not significantly change the proliferation rate of SKOV3 cells and the growth responsiveness of cells to $E_{2}$. Knockdown of LRP16 by RNA interference in SKOV3 cells markedly attenuated estrogen response elementdependent ER $\alpha$ reporter gene activity and $E_{2}$-induced $\mathrm{c}-\mathrm{Myc}$ expression. Our study suggests a novel mechanism of estrogen resistance of ovarian cancer by which estrogenrepressed signaling pathway antagonizes estrogen-activated signaling transduction.

Journal of Endocrinology (2009) 202, 167-177

\section{Introduction}

Estrogen plays a crucial role in the control of development, sexual behavior, and reproductive functions. Its effects have been linked to the onset and progression of gynecological malignancies including breast cancer and endometrial cancer (Shang 2006, Yager \& Davidson 2006, Eliassen \& Hankinson 2008). Estrogen, a major steroidal product of the ovary, has also been associated with increased ovarian cancer risk (Bai et al. 2000, Rodrigez et al. 2001, Riman et al. 2002). The biological effects of estrogens are mediated by two forms of estrogen receptor, $\operatorname{ER} \alpha$ and $\operatorname{ER} \beta$. Classically, $E R \alpha$ is activated by estrogen binding, which leads to receptor phosphorylation, dimerization, and recruitment of coactivators to the estrogen-bound receptor complex. This complex then binds promoter regions of target genes via direct interaction with DNA binding sites referred to as estrogen response elements (ERE) and initiate transcriptional activity (McDonnell \& Norris 2002). Estrogen-bound ER $\alpha$ can also transactivate additional target genes through interacting with other transcriptional factors such as Ap1, Sp1 or nuclear factor $\kappa B$ (Safe 2001, Shang \& Brown 2002,
DeNardo et al. 2005). The activation of an ER results in an altered expression of its direct transcriptional targets, thereby affecting downstream secondary biological activities. Estrogen regulation of protein expression has been well-documented in breast cancer models but till date little is known about estrogen-regulated gene expression in ovarian cancer.

Epithelial ovarian carcinoma, which represents about 90\% of ovarian cancer (Auersperg et al. 2001), is one of the most frequently occurring cancers among women and the leading cause of gynecological cancer deaths (Boente et al. 1993, Greenlee et al. 2000). Approximately two-thirds of all ovarian cancers express ER $\alpha$ at the time of diagnosis (Slotman \& Rao 1988). The significance of estrogen in the etiology of ovarian carcinoma has been emphasized by the fact that anti-estrogenic intervention will inhibit the growth of ovarian carcinoma in vivo and in vitro (Langdon et al. 1990, 1994a), and that estrogen replacement therapy induces ovarian cancer (Gompel \& Plu-Bureau 2007, Zhou et al. 2008). Cell-based studies have shown that estrogen-driven growth of epithelial ovarian carcinoma is mediated by activation of ER $\alpha$ mediated but not ER $\beta$-mediated transcription (O'Donnell et al. 2005). Although estrogens are believed to be major 
regulators of growth in the development and progression of ovarian carcinoma, ER $\alpha$-positive ovarian cancer is often unresponsive to estrogen and refractory to antiestrogen therapy (Smyth et al. 2007, Wagner et al. 2007). The ER $\alpha$ signaling pathway in estrogen-resistant ovarian cancer cells is poorly understood. Hence, characterizing ER $\alpha$-mediated gene expression in estrogen-insensitive ovarian cancer cells might underlie the unresponsiveness of ovarian cancer to estrogen and resistance to hormonal therapy. The SKOV3 human ovarian carcinoma cells, which have functional $\mathrm{ER} \alpha$ but are growth-resistant to estrogen and antiestrogens (Langdon et al. 1994b, Hua et al. 1995), were commonly used as an in vitro model for estrogen and antiestrogen resistant ovarian cancer (Havrilesky et al. 2001, O’Donnell et al. 2005).

LRP16 is a special member of macro domain superfamily, the structure of which is simple in contrast to other macro domain protein members, composed of only a stand-alone macro module at its C-terminal region (Han et al. 2002, Aguiar et al. 2005). LRP16 was previously identified as an estrogen-responsive target gene. Estrogen-induced upregulation of LRP16 expression is mediated by ER $\alpha$, but not by ER $\beta$ (Han et al. 2003). In cell culture, it has been shown that the expression level of LRP16 is strongly dependent on the estrogen actions in ER $\alpha$-positive breast and endometrial cancer cell lines (Han et al. 2007, Meng et al. 2007). A proximal region of -676 to $-24 \mathrm{bp}$ of the human LRP16 promoter, in which a 1/2 ERE/Sp1 site and multiple GC-rich elements that confer estrogen responsiveness have been recognized, is essential for estrogen action (Zhao et al. 2005, Han et al. 2008). Interestingly, estrogen-upregulated LRP16 can interact with ER $\alpha$ and enhance the receptor's transcriptional activity in a ligand-dependent manner, thus establishing a positive feedback regulatory loop between LRP16 and ER $\alpha$ signal transduction in estrogen-responsive breast cancer cells (Han et al. 2007). Overexpression of LRP16 can stimulate the proliferation of MCF-7 human breast cancer cells by enhancing estrogen-activated ER $\alpha$ transcriptional function (Han et al. 2007). In addition, inhibition of LRP16 gene expression significantly suppresses the invasive capacity of estrogen-responsive breast and endometrial cancer cells by upregulating E-cadherin expression via $E R \alpha$ mediation (Meng et al. 2007). Consistent with the findings from cell culture, the mRNA level of LRP16 was observed to be positively linked to the progression of primary breast cancers (Liao et al. 2006). These data implied that LRP16 may play an important role in carcinogenesis and/or progression of hormone-dependent cancers by a feed-forward mechanism that activated ER $\alpha$ transactivation. In addition, we recently demonstrated that LRP16 can be upregulated by androgen in the androgensensitive LNCaP prostate cancer cells and that LRP16 serves as an essential coactivator of androgen receptor (Yang et al. 2009). Although the regulatory mechanism of LRP16 expression by estrogen and the functional role of LRP16 in estrogen-sensitive epithelial tumor cells are relatively well documented, the estrogen induction and the functional significance of LRP16 gene in estrogen-unresponsive epithelial ovarian cancer cells are not clear so far.

In this study, we investigated the regulatory effects of estrogen, estrogen antagonist, and the unliganded-ER $\alpha$ on LRP16 gene expression and gene promoter activity in SKOV3 human ovarian cancer cells, with the aim to determine whether LRP16 is an estrogen-responsive gene in estrogen-unresponsive SKOV3 ovarian cancer cells. We also surveyed the effect of LRP16 expression on ER $\alpha$ mediated transcriptional activity by ERE-based reporter assay and the proliferation of SKOV3 cells to determine whether disruption of the ER $\alpha$-LRP16 feed-forward pathway in estrogen-resistant ovarian cancer cells can change the cell response to estrogen.

\section{Materials and Methods}

\section{Chemicals and cell lines}

$17 \beta$-Estradiol $\left(\mathrm{E}_{2}\right)$ was purchased from Sigma. Pure estrogen antagonist ICI 182780 was provided by Dr Qinong Ye at the College of Military Medicine Scientific Institute of China. Human ovarian epithelial adenocarcinoma cell line SKOV3 was originally purchased from American Type Culture Collection (ATCC, Rockville, MD, USA) and maintained as monolayer cultures in RPMI 1640 medium (Gibco) supplemented with 10\% (v/v) fetal bovine serum (FBS; Hyclone, Logan, UT, USA). BG-1 human ovarian epithelial cancer cell line was cultured as previously described (Geisinger et al. 1989). Steroid-deprived serum was prepared as previously described (Zhao et al. 2005).

\section{Plasmids}

The pGL3-Basic and pRL-SV40 were originally purchased from Promega. The pcDNA3.1-LRP16 expression vector containing human LRP16 full-length cDNA was previously constructed (Han et al. 2003). Mammalian expression plasmid for $\operatorname{ER} \alpha(\mathrm{pS} 5 \mathrm{G}-\mathrm{hER} \alpha)$ was provided by Prof. Hajime Nawata at Kyushu University, and the reporter $3 \times$ ERETATA-Luc was provided by Prof. Donald P McDonnell at Duke University Medical Center (Norris et al. 1998). The luciferase reporter constructs pGL3-S $\mathrm{S}_{0}$, pGL3- $\mathrm{S}_{2}, \mathrm{pGL} 3-\mathrm{S}_{4}$, pGL3- $S_{5}$, and $\mathrm{pGL} 3-\mathrm{S}_{\mathrm{B} 1}$, containing the fragment of -2623 to $-24 \mathrm{bp},-1775$ to $-24 \mathrm{bp},-1064$ to $-24 \mathrm{bp},-676$ to $-24 \mathrm{bp},-213$ to $-24 \mathrm{bp}$ of the LRP16 upstream regulatory region respectively, have been previously described (Zhao et al. 2005, Han et al. 2008).

\section{Cell transfection}

SKOV3 cells were seeded in $60 \mathrm{~mm}$ culture dishes before transfection. When the cell confluence reached $40-60 \%, 5 \mu \mathrm{g}$ pcDNA3.1-LRP16 was stably transfected using the Superfect 
transfection reagent (Qiagen), according to the manufacturer's instructions. The empty vector was used as a negative control. Two days post-transfection, the SKOV3 cells were treated with $1 \mathrm{mg} / \mathrm{ml} \mathrm{G} 418$ (Gibco) for 10-14 days and then were continuously cultured with $400 \mu \mathrm{g} / \mathrm{ml} \mathrm{G} 418$.

For siRNA transfection, SKOV3 cells were seeded in $60 \mathrm{~mm}$ culture dishes and grown to $80 \%$ confluence before transfection. SiRNA duplexes were transfected using Lipofectamine 2000 according to the manufacturer's recommendations (Invitrogen). SiRNA oligonucleotides were chemically synthesized by Shanghai GeneChem Co., Ltd (Shanghai, China). The sequences of LRP16-siRNA374 and LRP16-siRNA668 were previously reported (Han et al. 2007). The siRNA sequence against $\mathrm{ER} \alpha$ was referred as previously described (Cheng et al. 2007). The unrelated siRNA sequence (sense strand, 5'-TTCTCCGAACGTGCACGT- $3^{\prime}$ ) was used as a control. The siRNA duplex was transfected in each dish with a final concentration of $50 \mathrm{nM}$.

\section{Luciferase reporter assays}

SKOV3 cells were cultured with RPMI 1640 supplemented with $5 \%(\mathrm{v} / \mathrm{v})$ steroid-deprived FBS for at least 3 days, then were plated in $35 \mathrm{~mm}$ culture dishes. Cells that had reached a $50 \%$ confluency rate were transiently cotransfected using Superfect reagent. $0 \cdot 5 \mu \mathrm{g}$ luciferase reporters were cotransfected with or without $0.5 \mu \mathrm{g}$ ER $\alpha$ expression vector into cells. pRL-SV40 (10 ng), a renilla luciferase control vector, was added to each dish as an internal control to assess the transfection efficiency. The total DNA was adjusted to $2 \mu \mathrm{g} /$ dish with pBSK + empty plasmid. Thirty hours after transfection, cells were treated with $\mathrm{E}_{2}\left(10^{-8} \mathrm{M}\right)$ or dimethyl sulfoxide (DMSO) for an additional $12 \mathrm{~h}$. The cells were lysed and harvested using the dual-luciferase reporter assay system. Luciferase activity was measured using TD-20/20 ${ }^{n}$ Luminometry System (Promega). All experiments were performed in triplicate and repeated at least thrice.

\section{Cell proliferation assay}

A total of $1 \times 10^{4}$ viable cells were seeded in 24 -well plates. After cell attachment, the medium was replaced with $1 \mathrm{ml}$ fresh RPMI 1640 supplemented with 1\% (v/v) steroidstripped FBS and were treated with $\mathrm{E}_{2}\left(10^{-7}\right.$ or $\left.10^{-8} \mathrm{M} / \mathrm{l}\right)$ or DMSO in the same fresh medium and the medium was changed every 2 days. Cell number was counted by Trypan Blue exclusion method using a hemocytometer. Cell proliferation rate was quantified using CellTiter 96 Aqueous One Solution Cell Proliferation Assay (Promega). Each experiment was performed in triplicate and repeated on three occasions.

\section{RNA isolation and northern analysis}

Total RNA was isolated by the acid guanidinium thiocyanatephenol-chloroform method using Triblue reagent (Biotec Co., Beijing, China). The procedure of the northern blot analysis was previously described (Han et al. 2007). Briefly, $20 \mu \mathrm{g}$ total RNA was electrophoresed through a $1 \%(\mathrm{w} / \mathrm{v})$ agrose gel containing formaldehyde and was transferred to a Hybond $\mathrm{N}^{+}$membrane (Amersham). The membranes were hybridized using the following probes labeled with $\left[\alpha_{-}{ }^{32} \mathrm{P}\right] \mathrm{dCTP}$ by random priming: $550 \mathrm{bp}$ fragment of LRP16 (432-981 bp, NM_014067) and 267 bp of GAPDH (543-809 bp, NM_002046).

\section{Western blot and antibodies}

The expression of LRP16, ER $\alpha$ and GAPDH proteins were examined by western blot analysis as previously described (Han et al. 2007). Briefly, cell lysates were electrophoresed by SDS-PAGE using 12\% (w/v) acrylamide gels and blotted onto PVDF membranes (Amersham). Blots were probed with the primary antibodies, washed and then incubated with HRP-labeled secondary antibodies (Santa Cruz Biotechnology, Santa Cruz, CA, USA), and binding was detected using enhanced chemiluminesence. The rabbit anti-LRP16 antibody (1:3000) was used as previously described (Han et al. 2007). Rabbit anti-ER $\alpha$ (1:500) and c-Myc (1:200) were purchased from Santa Cruz. Mouse anti-GAPDH antibody (1:500) was purchased from Abcam (Cambridge, MA, USA).

\section{Chromatin immunoprecipitation assays}

SKOV3 cells $\left(1 \times 10^{6}\right)$ were grown in $10 \mathrm{~cm}$ tissue culture plates in RPMI 1640 supplemented with $10 \%$ (v/v) steroiddepleted FBS. After $24 \mathrm{~h}$, the cells were transfected with $10 \mu \mathrm{g}$ plasmid DNA mixture $\left(1: 1\right.$ for $\mathrm{pGL}_{3}-\mathrm{S}_{5}$ and $\mathrm{pS} 5 \mathrm{G}-$ hER $\alpha$ ) using Superfect reagent. Forty hours later, the transfected cells were treated with $\mathrm{E}_{2}\left(10^{-8} \mathrm{M} / \mathrm{l}\right)$ for $3 \mathrm{~h}$ and were subjected to chromatin immunoprecipitation (ChIP) assays. In addition, SKOV3 cells $\left(1 \times 10^{7}\right)$ treated with $\mathrm{E}_{2}\left(10^{-8} \mathrm{M} / \mathrm{l}\right)$ were also used for ChIP assays, which were performed as previously described (Meng et al. 2007). Briefly, immunoprecipitation was carried out overnight at $4{ }^{\circ} \mathrm{C}$ with ER $\alpha$ (Santa Cruz) antibody or non-specific IgG. DNA fragments were purified with a QIAquick Spin Kit (Qiagen). The presence of the target gene promoter sequences in both the input and the recovered DNA immunocomplexes was detected by PCR. The proximal promoter $(-476$ to $-241 \mathrm{bp})$ of LRP16 was amplified using the following primer set: forward primer, 5'-GCGCCAGGCTCTCCCAGCTCG-3', and reverse primer, 5'-CCCAGTGTCGCGGATGGAGC-3' .

\section{Statistical analyses}

Experiments were performed in triplicate and repeated at least thrice, and the results were expressed as the mean \pm s.E.M. Statistical analysis was performed using Statview 5.0 software. Paired Student's $t$-tests or two-way ANOVA followed by the 
Student-Newman-Keuls test were used where applicable to assess significant differences between groups. $P<0 \cdot 05$ was considered to be statistically significant.

\section{Results}

LRP16 expression is upregulated by $E_{2}$ in BG-1 cells, but is downregulated in SKOV3 cells

Previously published work from our laboratory demonstrated that $E_{2}$ upregulated the level of the human LRP16 gene through $\mathrm{ER} \alpha$ activation in several $\mathrm{E}_{2}$-responsive human breast and endometrial cancer cells (Han et al. 2007, Meng et al. 2007). Here, to address whether LRP16 can be induced by $E_{2}$ in ER $\alpha$-positive human ovarian cancer BG-1 and SKOV3 cells, we performed northern blot analysis. As seen in Fig. 1A, the mRNA expression level of LRP16 was upregulated by $E_{2}\left(10^{-8} \mathrm{M} / \mathrm{l}\right)$ in $\mathrm{BG}-1$ cells as it was in MCF-7 and Ishikawa cells (Han et al. 2003, Meng et al. 2007). However, in SKOV3 cells, LRP16 expression was not upregulated by $\mathrm{E}_{2}$ treatment; conversely, it was downregulated by $E_{2}$ in a does-dependent fashion (Fig. 1B). Compared with the LRP16 expression level in cells cultured under steroid-deprived culture conditions (Fig. 1B lane 1), a dramatic decrease was observed in cells under normal conditions (FBS without steroid deprivation) (Fig. 1B, lane 6), indicating that the endogenous estrogen in culture medium is enough to suppress LRP16 expression after a long-term exposure of cells to it. To confirm that the LRP16 mRNA
A

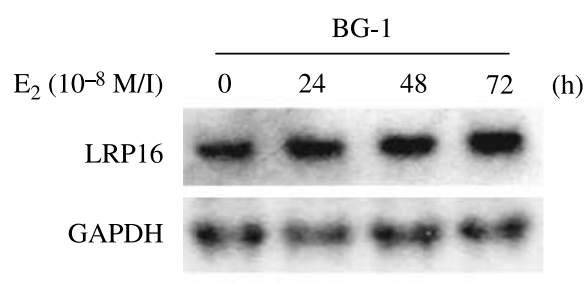

C

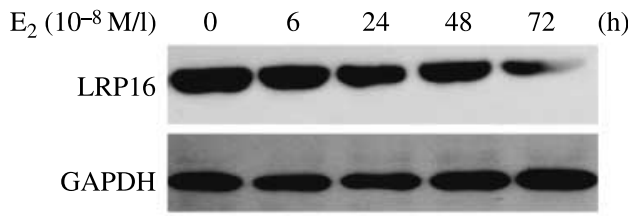

B

$\mathrm{E}_{2}(\mathrm{M} / \mathrm{l})$

LRP16

GAPDH

LRP16

GAPDH

\begin{tabular}{llllll}
\multicolumn{6}{c}{ SKOV3 } \\
\hline 0 & $10^{-9}$ & $10^{-8}$ & $10^{-7}$ & $10^{-6}$ & $\mathrm{~N}$
\end{tabular}

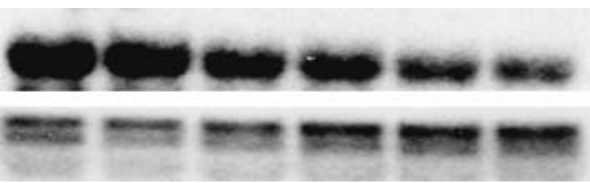

Northern blot

(24h)

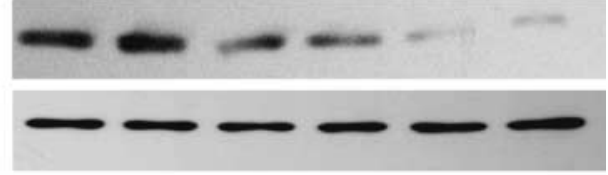

Western blot

E

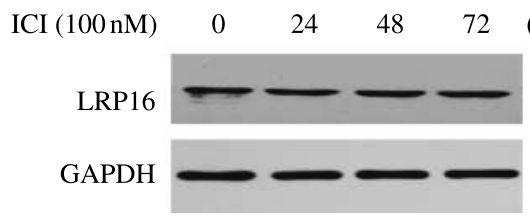

D

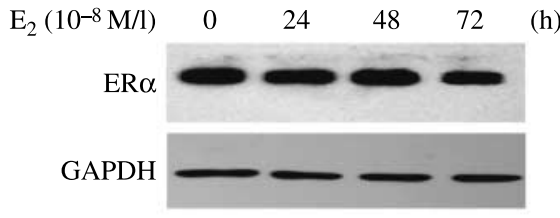

(h)

$\mathrm{E}_{2}\left(10^{-8} \mathrm{M} / \mathrm{l}\right)$

(h) ICI $(100 \mathrm{nM})$

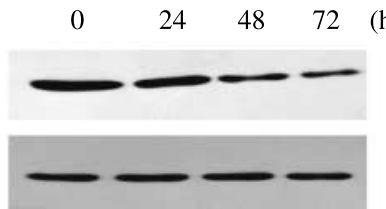

Figure $1 \mathrm{E}_{2}$ regulation of LRP16 expression in BG-1 and SKOV3 cells. (A) BG-1 cells were cultured in medium containing steroid-stripped FBS for at least 3 days, and then were treated with $E_{2}$ at $10^{-8} \mathrm{M} / \mathrm{I}$ for the indicated time points. The total RNA was extracted and the expression level of LRP16 mRNA was determined by northern blot analysis. Total RNA was used as the loading control. (B) SKOV3 cells were cultured in medium containing steroid-stripped FBS for at least 3 days, and then were treated with various concentrations of $\mathrm{E}_{2}$ from $10^{-9}$ to $10^{-6} \mathrm{M} / \mathrm{I}$ for $24 \mathrm{~h}$. LRP16 mRNA level was determined by northern blot analysis. Total RNA was used as the loading control. Western blots were probed for LRP16 and GAPDH. N, cells were cultured in medium containing FBS without steroid deprivation. (C and D) SKOV3 cells were cultured in medium containing steroid-stripped FBS for at least 3 days, and then were treated with $\mathrm{E}_{2}$ at $10^{-8} \mathrm{M} / \mathrm{l}$ for the indicated time points. Immunoblots were probed for LRP16, ER $\alpha$ and GAPDH. (E) SKOV3 cells were cultured in routine culture medium and were treated with ICI 182780 for the indicated times (left panel). SKOV3 cells were cultured in medium containing steroid-stripped FBS for at least 3 days, treated with $\mathrm{E}_{2}$ and $\mathrm{ICI} 182780$, and then were cultured for the indicated time points (right panel). Immunoblots were probed for LRP16 and $\mathrm{GAPDH}$. The experiments shown in A-E were repeated at least thrice. 
levels were indicative of protein levels, the expression level of LRP16 protein was examined in $\mathrm{E}_{2}$-treated $\mathrm{SKOV} 3$ cells using western blot analysis and the results showed the consistent change with that observed at the mRNA level (Fig. 1B). Next, we performed western blot analysis to determine the time course for the effect of $E_{2}\left(10^{-8} \mathrm{M} / \mathrm{l}\right)$ on the expression level of LRP16 protein in SKOV3 cells, over a $72 \mathrm{~h}$ time-period (Fig. 1C). A more than twofold decrease in LRP16 protein level was observed as early as $6 \mathrm{~h}$ after addition of $E_{2}$, and this was continued to $48 \mathrm{~h}$. At $72 \mathrm{~h}$ after treatment of $E_{2}$, the expression of LRP16 protein decreased to a much lower level. To rule out the possibility that $E_{2}$-induced LRP16 decrease resulted from altered ER $\alpha$ expression, we measured the ER $\alpha$ protein levels in $\mathrm{E}_{2}$-treated cells. As shown in Fig. $1 \mathrm{D}, \mathrm{E}_{2}$ treatment $\left(10^{-8} \mathrm{M} / \mathrm{l}\right)$ did not significantly change the expression of ER $\alpha$ protein during the $72 \mathrm{~h}$ time course. These results demonstrated that LRP16 is not an estrogen upregulated target gene in estrogen-insensitive SKOV3 ovarian carcinoma cells as it is in estrogen-responsive epithelial cancer cells, but is an estrogen downregulated gene which exhibits a sensitive and continuous response to $E_{2}$ treatment.

To assess the effect of antiestrogen on the expression level of LRP16 in SKOV3 cells, the selective estrogen antagonist, ICI $182780(100 \mathrm{nM})$ was used to treat proliferating cells. Total protein over a $72 \mathrm{~h}$ time course was extracted and western blot analysis was used to determine the LRP16 protein level. As shown in Fig. 1E (left panel), there was no significant increase of LRP16 protein level in cells after ICI 182780 addition. The LRP16 protein level was downregulated by the addition of $E_{2}\left(10^{-8} \mathrm{M} / 1 \mathrm{E}_{2}\right)$ even in the presence of ICI 182780 (Fig. 1E, right panel), indicating that antiestrogen treatment can not effectively antagonize the $\mathrm{E}_{2}$ suppression of LRP16 expression in estrogen-resistant ovarian cancer cells.

\section{Unliganded ER $\alpha$ up-regulates LRP16 gene expression/gene promoter activity in SKOV3 cells}

To determine whether the inhibitory effect of LRP16 expression by $\mathrm{E}_{2}$ in SKOV3 cells is mediated by $\mathrm{ER} \alpha$, we investigated the induction effects of unliganded $\operatorname{ER} \alpha$ on LRP16 expression by performing western blot analysis in ER $\alpha$-transfected SKOV3 cells. As illustrated in Fig. 2A, ER $\alpha$ protein level was dramatically increased in ER $\alpha$-transfected cells. The protein level of LRP16, but not GAPDH, was markedly increased by the ectopic ER $\alpha$ expression in cells; however, this elevation was reduced by $E_{2}$ treatment (Fig. 2A). To further address the regulatory effect of unliganded ER $\alpha$ on LRP16 expression, we also measured the LRP16 expression in ER $\alpha$-inhibited SKOV3 cells. Results from immunoblotting analysis showed that not only the endogenous ER $\alpha$ was largely repressed by ER $\alpha$-specific siRNA transfection, but also the endogenous LRP16 (Fig. 2B). These findings confirmed that the non- $\mathrm{E}_{2}$ bound ER $\alpha$ efficiently induces LRP16 expression in SKOV3 cells, but this induction can be blocked by $\mathrm{E}_{2}$ binding.
A

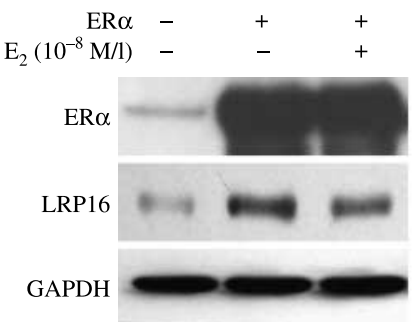

B

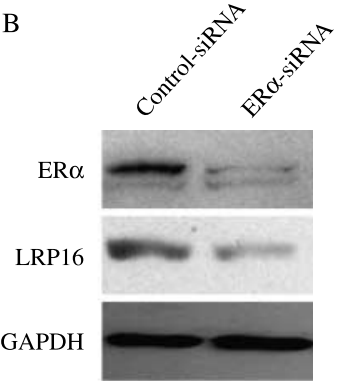

Figure $2 \mathrm{ER} \alpha$ regulation of LRP16 expression in SKOV3 cells. (A) SKOV3 cells were first cultured in steroid-stripped medium for at least 3 days, and then were transiently transfected with $E R \alpha$ expression vector or empty vector. Thirty-six hours after transfection, cells were treated with or without $\mathrm{E}_{2}\left(10^{-8} \mathrm{M} / \mathrm{l}\right)$ and cultured for an additional $12 \mathrm{~h}$. Immunoblots were probed for ER $\alpha$, LRP16 and GAPDH. (B) SKOV3 cells were cultured in steroid-deprived medium for at least 3 days, and then were transfected with the $E R \alpha$ specific siRNA or the control-siRNA oligonucleotides. Forty-eight hours after transfection, total protein was extracted and subjected to immunoblotting analysis using the indicated antibodies. The experiments shown in A and B were repeated at least thrice.

To further address the regulatory roles of liganded and unliganded $\mathrm{ER} \alpha$ on the transcriptional activities of LRP16 gene in SKOV3 cells, we performed luciferase reporter assays with a series of LRP16 promoter-driving luciferase constructs. Transfection of SKOV3 cells with reporter alone revealed background luciferase activities (Fig. 3). Cotransfection of $\mathrm{ER} \alpha$ did not significantly change the luciferase activities for pGL3-S $\mathrm{S}_{\mathrm{B} 1}$ and the control vector pGL3-Basic, but indeed resulted in a two- to fourfold increase of reporter gene activities for pGL3-S 0 , pGL3-S $\mathrm{S}_{2}, \mathrm{pGL} 3-\mathrm{S}_{4}$ and pGL3-S $S_{5}$ constructs (Fig. 3). However, the unliganded ER $\alpha$ activation of LRP16 promoter constructs was effectively blocked by $E_{2}$ treatment $\left(10^{-8} \mathrm{M} / \mathrm{l}\right)$. These findings further confirmed the distinct regulation of unliganded and liganded $\mathrm{ER} \alpha$ on the transcriptional activity of LRP16 gene and suggested that this regulation may be mainly conferred by the fragment from -676 to -214 bp of LRP16 upstream region.

\section{$E_{2}$ inhibits the recruitment of $E R \alpha$ to LRP16 gene promoter}

To analyze whether the increased promoter activity of LRP16 by unliganded ER $\alpha$ is the direct result of recruitment of $\operatorname{ER} \alpha$, we performed ChIP assays. The LRP16 promoter containing construct pGL3- $\mathrm{S}_{5}$, which was authenticated to be activated by $\operatorname{ER} \alpha$ in the absence of $E_{2}$ as illustrated in Fig. 3, together with ER $\alpha$ expression vector was cotransfected into SKOV3 cells. The cells were then treated with or without $\mathrm{E}_{2}\left(10^{-8} \mathrm{M} / \mathrm{l}\right)$ for $3 \mathrm{~h}$, and the recruitment of ER $\alpha$ was analyzed by ChIP (Fig. 4A). In the absence of $\mathrm{E}_{2}$ treatment, we repeatedly detected a high level of ER $\alpha$ binding at the promoter of LRP16. However, ER $\alpha$ was apparently lost from the LRP16 promoter after estrogen treatment. As a control experiment, the fragment of -476 to $-241 \mathrm{bp}$ was not detected in the non-specific IgG group. 

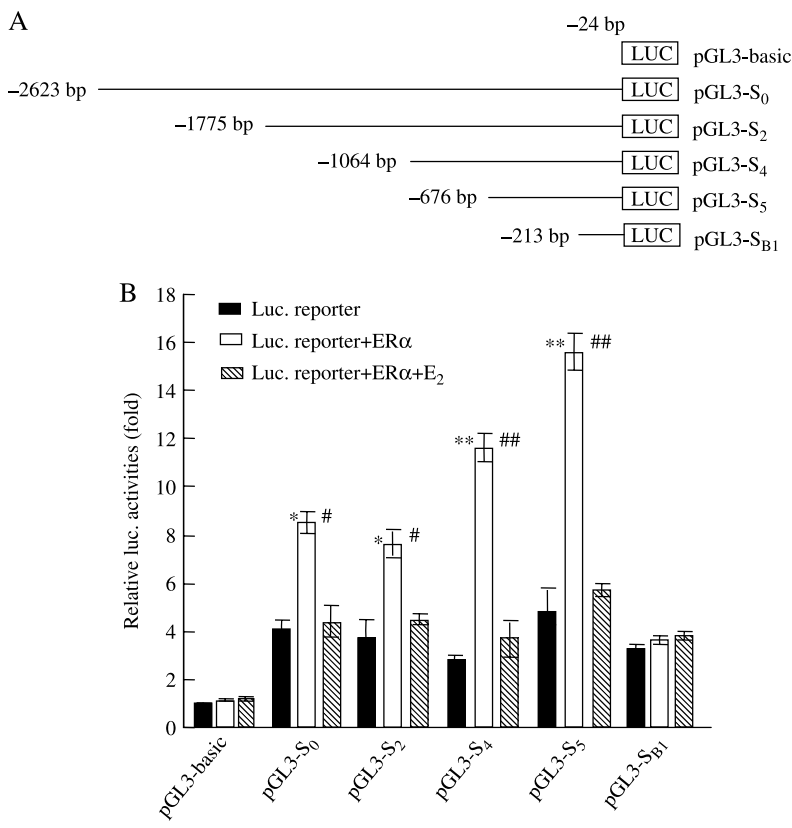

Figure 3 Unliganded and liganded $E R \alpha$ regulation of $L R P 16$ gene promoter activity in SKOV3 cells. (A) The graphic illustration of luciferase reporters driven by different LRP16 promoter fragments. (B) SKOV3 cells were cultured in steroid-deprived medium for at least 3 days, and then were cotransfected with the indicated vectors. pRL-SV40 was also transfected to assess the transfection efficiency. Thirty hours after transfection, cells were treated with $\mathrm{E}_{2}\left(10^{-8} \mathrm{M}\right)$ or dimethyl sulfoxide (DMSO) for an additional $12 \mathrm{~h}$ and underwent luciferase assay. The relative luciferase activity levels were normalized in all cases by mock effector transfection and arbitrarily assigned a value of 1 . All experiments were performed in triplicate and were repeated at least thrice; results are expressed as mean \pm s.E.M. Two-way ANOVA followed by the Student-Newman-Keuls test were performed for assessing significant differences between groups ${ }^{*} P<0 \cdot 05, * * P<0 \cdot 01$, comparison between $\mathrm{ER} \alpha$ transduction-induced activity with respective basal activity. ${ }^{\sharp} P<0 \cdot 05$,

${ }^{\# \#} P<0 \cdot 01$, comparison between ER $\alpha$ transduction-induced activity with $E R \propto$ transduction and $E_{2}$ treatment-induced activity.

Next, we performed ChIP-analyses of the endogenous LRP16-promoter ( -476 to $-241 \mathrm{bp}$ ) and the results showed that binding of unliganded $E R \alpha$ occurs at the natural, endogenous promoter in the estrogen-resistant SKOV3 cells, and that this is lost after $\mathrm{E}_{2}$ treatment (Fig. 4B). These results indicated that LRP16 is a primary target gene of the unliganded ER $\alpha$ in SKOV3 cells.

LRP16 does not significantly modulate the growth responsiveness of $S K O V 3$ cells to $E_{2}$

Previous reports from our laboratory demonstrated that overexpression of LRP16 promotes proliferation of estrogen sensitive MCF-7 breast cancer cells (Han et al. 2003). To investigate the effect of LRP16 on SKOV3 cell growth, we stably transfected pcDNA3.1-LRP16 or pcDNA3.1 empty vector into SKOV3 cells and performed cell proliferation assays. After 10 to 14-day G418 screening, the drug-resistant
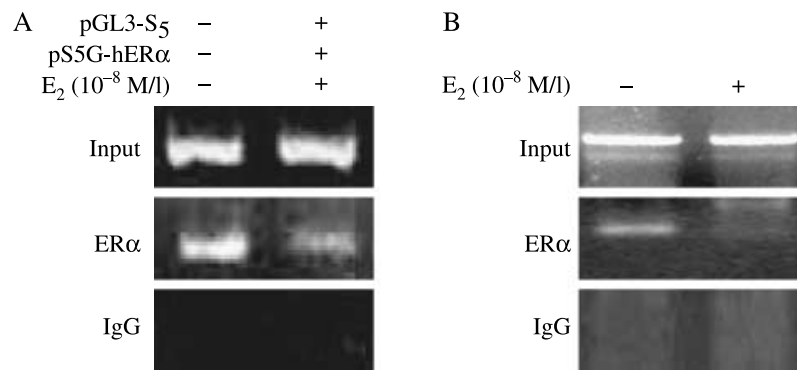

Figure $4 E_{2}$ inhibition of ER $\alpha$ recruitment to LRP16 gene promoter in SKOV3 cells. (A) SKOV3 cells were transiently cotransfected with $\mathrm{ER} \alpha$ and $\mathrm{pGL} 3-\mathrm{S}_{5}$. Forty hours after transfection, the cells were treated with $\mathrm{E}_{2}\left(10^{-8} \mathrm{M} / \mathrm{l}\right)$ or DMSO for $3 \mathrm{~h}$ and were subjected to immunoprecipitation and PCR as described in 'Materials and Methods'. (B) SKOV3 cells were treated with $E_{2}\left(10^{-8} \mathrm{M} / \mathrm{l}\right)$ or DMSO for $3 \mathrm{~h}$ and were subjected to immunoprecipitation and PCR as described in A. The experiments shown in A and B were repeated thrice.

clones appeared and were mixed for amplified culture. All of the parental cells were killed by G418 within this period. The expression level of LRP16 was measured within 30 days after transfection by western blot analysis and the results showed that the ectopic transfection markedly increased the LRP16 expression (Fig. 5A). As shown in Fig. 5B, LRP16 overexpression did not significantly promote SKOV3 cell proliferation either in the absence or presence of $\mathrm{E}_{2}$ treatment. Next, we transiently transfected LRP16 specific siRNAs or control-siRNA into SKOV3 cells to evaluate the effect of LRP16 knock-down on cell proliferation. Compared with the control-siRNA, both LRP16-siRNA374 and LRP16siRNA668 caused a specific reduction of LRP16 expression at protein level, but did not change the expression level of the GAPDH gene (Fig. 6A). Consistent with our previous report (Han et al. 2007), LRP16-siRNA374 was reproducibly better than LRP16-siRNA668 and was used more frequently in later experiments. Significant difference of cell growth between LRP16-siRNA and control-siRNA transfected cell groups was not observed at any time point during the culture period when the cells were cultured without $\mathrm{E}_{2}$ stimulation. Similarly, the growth rate of SKOV3 cells was not markedly altered by LRP16 knockdown when the cells were treated with $\mathrm{E}_{2}$ (Fig. 6B). By immunoblotting analysis, we observed that the endogenous LRP16 in SKOV3 cells still can be partially inhibited by LRP16-siRNA 374 at day 7 after transfection (Fig. 6C). These findings suggested that LRP16 does not significantly modulate the growth responsiveness of the estrogen-resistant ovarian cancer cells to estrogen.

\section{LRP16 modulates ER $\alpha$-mediated signaling transduction in SKOV3 cells}

Although the growth of SKOV3 cells is insensitive to $\mathrm{E}_{2}$ stimulation, the normal estrogen regulation of an EREdriven reporter gene activity and a few ER $\alpha$ target genes such as c-Myc and c-fos in $\mathrm{E}_{2}$-sensitive breast cancer cells can still 

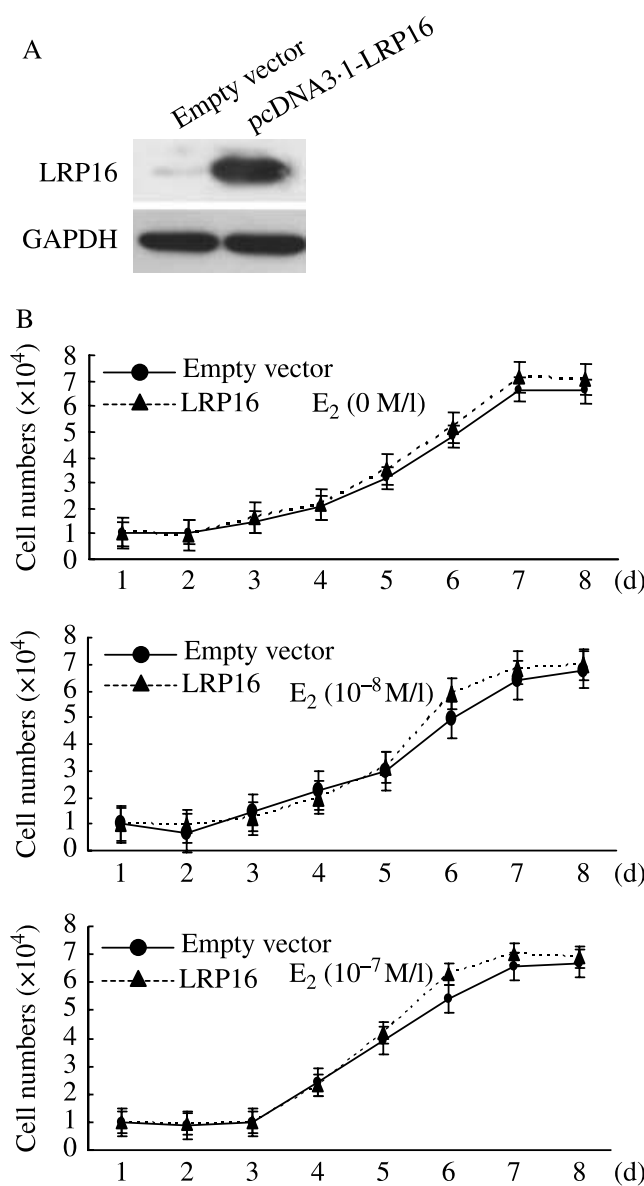

Figure 5 Effect of overexpression of LRP16 in SKOV3 cells on cell proliferation. (A) SKOV3 cells were stably transfected with LRP16 or pcDNA3.1 empty vector. Immunoblots were probed for LRP16 and DAPDH within 30 days after transfection. (B) SKOV3 cells expressing ectopic LRP16 or empty vector were cultured in steroiddeprived medium for at least 3 days and treated with $E_{2}\left(10^{-7}\right.$ or $10^{-8} \mathrm{M} / \mathrm{l}$ ) or DMSO. The cell number was determined by Trypan Blue exclusion method. Each data point represents the mean \pm s.E.M. number of cells counted in triplicate dishes from at least three independent experiments. Student's $t$-test was performed between values. No significant difference was observed at each data point between the indicated two cell groups $(P>0 \cdot 05)$.

be observed in SKOV3 cells (Hua et al. 1995). To determine whether LRP16 functions as an active ER $\alpha$ coactivator in SKOV3 cells as it does in estrogen-dependent ER $\alpha$-positive epithelial cancer cells, we tested the effect of LRP16 expression on ER $\alpha$-mediated transcription by using a $3 \times$ ERE-TATA-Luc reporter construct. SKOV3 cells were cultured in steroid-stripped medium for at least 3 days, and then were cotransfected with $3 \times$ ERE-TATA-Luc, ER $\alpha$ and LRP16-siRNA374, LRP16-siRNA668 or control-siRNA. As shown in Fig. $7 \mathrm{~A}, \mathrm{E}_{2}\left(10^{-8} \mathrm{M} / \mathrm{l}\right)$ stimulation elicited a twofold increase of ER $\alpha$-mediated reporter gene activity in control-siRNA expressing cells, which was in agreement with the previous report (Hua et al. 1995). However, only
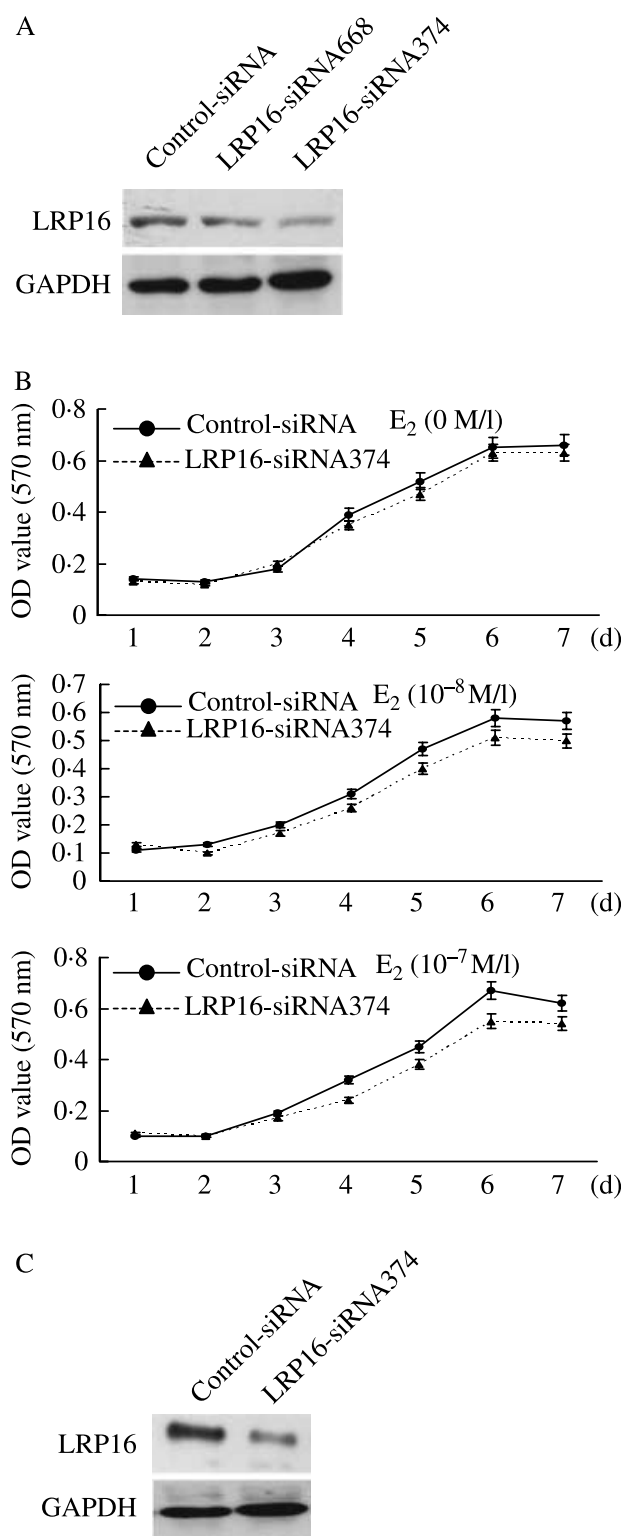

Figure 6 Effect of LRP16 knock-down in SKOV3 cells on cell proliferation. (A) SKOV3 cells were cultured in steroid-deprived medium for at least 3 days and transfected with LRP16-siRNA 374, LRP16-siRNA668 or control-siRNA. Forty-eight hours after transfection, total protein was extracted and subjected to immunoblotting analysis using the indicated antibodies. (B) SKOV3 cells were cultured in medium supplemented with steroid-stripped FBS $(5 \%, v / v)$ for 3 days and then transiently transfected with LRP16siRNA374 or control-siRNA. Forty-eight hours after transfection, cells were treated with $E_{2}$ at different concentrations for the indicated times. Cell proliferation rate was quantified by CellTiter 96 AQueous assay. Each data point represents the mean \pm s.E.M. of at least three independent experiments. Student's t-test was performed between values. No significance difference was observed at each data point between the indicated two cell groups $(P>0 \cdot 05)$. (C) SKOV3 cells transfected with the indicated siRNAs were cultured in steroid-deprived medium for 7 days. Immunoblots were probed for LRP16 and GAPDH. 

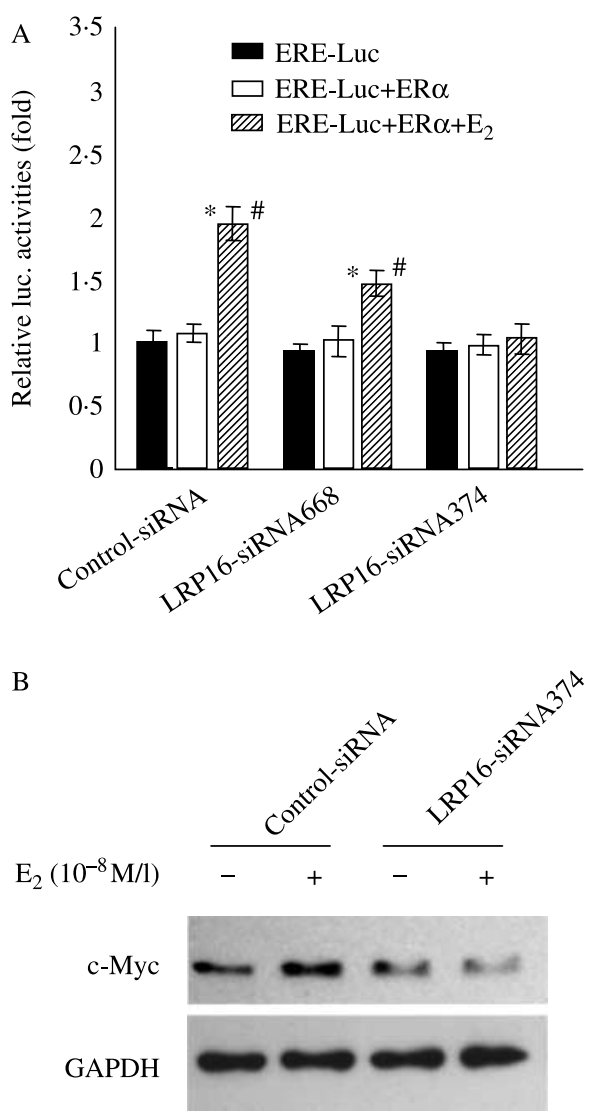

Figure 7 Effect of LRP16 knock-down on ER $\alpha$-activated ERE-dependent transactivation and $\mathrm{E}_{2}$-induced c-Myc expression in SKOV3 cells. (A) SKOV3 cells were grown in media stripped of steroids for at least 3 days, then cotransfected with $3 \times$ ERE-TATALuc reporter and the effector molecule ER $\alpha$ and LRP16-siRNAs or control-siRNA oligonucleotides. The relatively normalized luciferase activity level for control-siRNA transfections were arbitrarily assigned a value of 1 . All experiments were performed in triplicate and were repeated at least three times; results are expressed as mean \pm s.E.M. Two-way ANOVA followed by the StudentNewman-Keuls test were used to assess significant differences between groups. ${ }^{*} P<0 \cdot 05$, comparison between $\mathrm{E}_{2}$-induced activity with respective basal activity. ${ }^{\sharp} P<0 \cdot 05$, comparison between $\mathrm{E}_{2}$-induced activity with only $E R \alpha$-transducted activity. (B) SKOV3 cells were cultured in steroid-stripped medium for at least 3 days, then transiently transfected with the indicated siRNA oligonucleotides. Forty-eight hours after transfection, cells were treated with $\mathrm{E}_{2}$ or DMSO for an additional $3 \mathrm{~h}$. Immunoblots were probed for C-Myc and GAPDH.

a 1.5-fold increase of the reporter gene activity by $E_{2}$ stimulation was observed in LRP16-siRNA668 transfected cells, and a $0 \cdot 1$-fold increase in LRP16-siRNA374 transfected cells. Next, we measured the $\mathrm{E}_{2}$ induction of c-Myc protein in LRP16-inhibited SKOV3 cells. As illustrated in Fig. $7 \mathrm{~B}, \mathrm{E}_{2}$ induced an increase of $\mathrm{c}-\mathrm{Myc}$ protein expression in control-siRNA expressing SKOV3 cells, which is consistent with that in MCF-7 cells as reported previously (Han et al. 2007); however, this induction was blocked by LRP16 knockdown. These results suggested that LRP16 is required for $E_{2}$-stimulated $E R \alpha$ signaling transduction and inhibition of LRP16 expression can efficiently suppress ER $\alpha$ mediated transcription activity and target gene expression.

\section{Discussion}

The mechanisms underlying the estrogen-independent, antiestrogen-resistant ovarian cancer are poorly understood despite being a major problem in endocrine therapy. In estrogen-sensitive BG-1 and estrogen-insensitive SKOV3 ovarian carcinoma cells, we demonstrate the inverse regulation of LRP16 expression by $\mathrm{E}_{2}$. Consistent with our previous report (Han et al. 2007), $\mathrm{E}_{2}$ can induce LRP16 expression in estrogen-sensitive BG-1 cells, whereas LRP16 was repressed in SKOV3 cells. As a functioning ER $\alpha$ coactivator, decreased expression of LRP16 in SKOV3 cells is capable of attenuating estrogen-activated ERE-dependent reporter gene activity and gene expression such as c-Myc. Our observations suggest an estrogen-repressed signaling pathway in estrogen-resistant ovarian cancer cells, which in turn antagonizes the 'classical' ER $\alpha$-activated signaling transduction. The antagonism between these two parallel estrogen signaling pathways underscores a novel mechanism of estrogen unresponsiveness of ovarian cancer.

Recently, it has been revealed that estrogen action is mediated by complex signaling pathways. Although it is believed that estrogen exerts most of its effects through direct activation of ER-regulated gene expression, this being the genomic or classical action of ER $\alpha$ (Cheskis et al. 2007, Heldring et al. 2007), several lines of evidence demonstrate the existence of an estrogen-repressed signaling pathway in various estrogen target cells and it is possibly linked to the pathogenesis of some diseases (Zubairy \& Oesterreich 2005, Cheskis et al. 2007). For example, transcriptional activation of proliferative genes by estrogen is associated with breast cancer (Foster et al. 2001) and transcriptional repression of cytokine genes by estrogen underlines an important mechanism whereby estrogen prevents inflammatory diseases associated with menopause (Ammann et al. 1997, Pfeilschifter et al. 2002, Pai et al. 2004). Even in estrogen-sensitive MCF-7 breast cancer cells and PEO-1 ovarian cancer cells, the number of estrogen downregulated genes is nearly equal to that of estrogen up-regulated genes (Charpentier et al. 2000, O'Donnell et al. 2005). The observation of estrogen repression of $L R P 16$ gene expression in SKOV3 cells suggests the existence of an estrogen-repressed signaling pathway in estrogen-resistant ovarian cancer cells. Moreover, the involvement of LRP16 in the classic estrogen-activated signaling suggests crosstalk between estrogen-repressed and estrogen-activated pathways in estrogen-insensitive ovarian cancer cells. The crosstalk between different ER $\alpha$-mediated signaling pathways was also observed in other cases. For instance, results from the analysis of a non-classical ER $\alpha$ knock-in mice model suggested crosstalk between EREdependent and independent $\operatorname{ER} \alpha$ signaling pathways and 
their alterations can result in a markedly aberrant response to estrogen (Syed et al. 2005, 2007).

Some genes, identified as being estrogen-regulated in estrogen-sensitive cells, have previously been shown to be estrogen targets in estrogen-insensitive cells. For example, estrogen can induce expression of the early growth response genes c-Myc and c-fos in both MCF-7 and SKOV3 cells (Hua et al. 1995, Prall et al. 1998). However, several genes are differentially regulated by estrogen in different cell contexts. For instance, Cyr61 is upregulated by estrogen in PEO-1 ovarian cancer cells (O'Donnell et al. 2005), but is downregulated in MCF-7 cells (Sampath et al. 2001). FN1 is downregulated in PEO-1 cells (O'Donnell et al. 2005) yet is upregulated in other cell types (Woodward et al. 2001, Mercier et al. 2002). In this study, the effects of estrogen on LRP16 expression observed in estrogen-sensitive cancer cells opposed the effect observed in estrogen-insensitive SKOV3 cells. The differential induction of LRP16 expression by liganded and unliganded ER $\alpha$ in SKOV3 cells revealed a completely different regulatory mechanism compared with that in estrogen-sensitive cancer cells. A proximal region of -676 to $-24 \mathrm{bp}$ of the human LRP16 promoter was previously identified to be essential for estrogen induction of LRP16 expression in MCF-7 cells (Han et al. 2008). Estrogen induces LRP16 gene transactivation by stimulating the interaction and recruitment of ER $\alpha$ and Sp1 transcription factor at a 1/2 ERE/ GC-rich site and multiple GC-rich sites present in -676 to $-24 \mathrm{bp}$ of the upstream regulatory region of LRP16 gene (Zhao et al. 2005, Han et al. 2008). By promoter analysis, we demonstrate that the fragment from -676 to -214 bp of the LRP16 upstream regulatory region mainly confers estrogen-repressed effect of LRP16 expression (Fig. 3). The observation that $\operatorname{ER} \alpha$ is able to bind to this region in the absence of estrogen stimulation by ChIP analysis revealed that LRP16 is a primary target of ER $\alpha$. Similarly, estrogen-repressed cyclin G2, tumour necrosis factor $\alpha(\mathrm{TNF} \alpha)$ and E-cadherin genes are also ER $\alpha$ primary target genes (Oesterreich et al. 2003, Cvoro et al. 2006, Stossi et al. 2006). Similar to the binding of unliganded ER $\alpha$ to the promoter region of LRP16 gene, the unliganded ER $\alpha$ can bind to the AP1/NF- $\kappa B$ element of $\mathrm{TNF} \alpha$ promoter region and enhance its transcription; however, it will be removed from TNF $\alpha$ promoter region as in the case of LRP16 gene after estrogen treatment (Cvoro et al. 2006). Unliganded ER $\alpha$ can enhance cyclin G2 transcription by binding to a $1 / 2$ ERE/Sp1 site within its promoter, or enhance E-cadherin transcription by binding to the most proximal region of its promoter, which does not contain any classical ERE but three E-boxes. Similarly, ER $\alpha$ will be removed from the binding sites of cyclin G2 and E-cadherin genes upon estrogen stimulation (Oesterreich et al. 2003, Stossi et al. 2006). By computer-based analysis, three sites including a 1/2 ERE/ GC-rich Sp1 site, a NF- $\mathrm{B}$ response element and an E-box site within the fragment from -676 to -214 bp of LRP16 upstream regulatory region were found, which may be the possible estrogen response sites. The detailed molecular mechanism of estrogen repression of LRP16 expression in SKOV3 cells is under investigation in our laboratory.

Increasing evidence revealed the existence of a selffeedback regulation loop in steroid nuclear receptormediated signaling pathway (Zwijsen et al. 1997, Shi et al. 2001, Lauritsen et al. 2002, Hong et al. 2005). LRP16 is upregulated by estrogen in estrogen-sensitive epithelial cancer cells, and in turn, it enhances ER $\boldsymbol{\alpha}$-activated signaling transduction in a ligand-dependent manner by interacting with the receptor (Han et al. 2007). As a coactivator, we have previously demonstrated that LRP16 is required for ER $\alpha$ mediated transactivation and involved in proliferation of estrogen-responsive breast cancer cells (Han et al. 2007). This feed-forward mechanism for ER $\alpha$ activation may reflect the self-maintaining nature of ER $\alpha$ signaling in estrogen-sensitive target cells and may be involved in the progression of estrogen-dependent cancers. So, disruption of ER $\alpha$ feed-forward activation pathway such as by blocking estrogen-induced LRP16 upregulation may predispose estrogen-sensitive cells to insensitive cells. This opinion was supported by our previous observation that knock-down of LRP16 in estrogen-dependent MCF-7 cells impaired estrogen-stimulated growth (Han et al. 2007). However, as we demonstrated in this study (Figs 5 and 6), the ectopic modulation of LRP16 expression in estrogen-insensitive SKOV3 cells did not significantly change cell proliferation rate and the growth response to $E_{2}$ treatment. This observation suggested that the estrogen repression of LRP16 expression in SKOV3 cells may not sufficiently induce the resistance of cells to estrogen.

In general, these findings clearly verified that $L R P 16$ is an estrogen-repressed target in estrogen-resistant SKOV3 human ovarian cancer cells. As we previously demonstrated, LRP16 can also exert its enhanced effect on the classical ER $\alpha$ mediated transcription by functioning as an ER $\alpha$ coactivator in SKOV3 cells.

\section{Declaration of interest}

All authors declare that there is no conflict of interest.

\section{Funding}

This study was supported by the National Natural Science Foundation of China (grants 30670809, 30572096), partially supported by a grant from the Ministry of Science and Technology of China (2005CB522603).

\section{Acknowledgements}

We thank Prof. Donald P McDonnell from Duke University Medical Center for providing $3 \times$ ERE-TATA-Luc plasmid and thank Dr Hajime Nawata at Kyushu University of Japan for his kind donation of the ER $\alpha$ expression vector. 


\section{References}

Aguiar RCT, Takeyama K, He C, Kreinbrink K \& Shipp MA 2005 $\mathrm{B}$-aggressive lymphoma family protein have unique domains that modulate transcription and exhibit poly(ADP-ribose) polymerase activity. Journal of Biological Chemistry 280 33756-33765.

Ammann P, Rizzoli R, Bonjour JP, Bourrin S, Meyer JM, Vassalli P \& Garcia I 1997 Transgenicmice expressing soluble tumor necrosis factor-receptor are protected against bone loss caused by estrogen deficiency. Journal of Clinical Investigation 99 1699-1703.

Auersperg N, Wong AS, Choi KC, Kang SK \& Leung PC 2001 Ovarian surface epithelium: biology, endocrinology, and pathology. Endocrine Reviews 22 255-288.

Bai W, Oliveros-Saunders B, Wang Q, Acevedo-Duncan ME \& Nicosia SV 2000 Estrogen stimulation of ovarian surface epithelial cell proliferation. In Vitro Cellular \& Developmental Biology. Animal 36 657-666.

Boente MP, Hurteau J, Rodriguez GC, Bast RC Jr \& Berchuck A 1993 The biology of ovarian cancer. Current Opinion in Oncology 5 900-907.

Charpentier AH, Bednarek AK, Daniel RL, Hawkins KA, Laflin KJ, Gaddis S, MacLeod MC \& Aldaz CM 2000 Effects of estrogen on global gene expression: identification of novel targets of estrogen action. Cancer Research 60 5977-5983.

Cheng JW, Yu DV, Zhou JH \& Shapiro DJ 2007 Tamoxifen induction of CCAAT enhancer-binding protein $\alpha$ is required for tamoxifen-induced apoptosis. Journal of Biological Chemistry 282 30535-30543.

Cheskis BJ, Greger JG, Nagpal S \& Freedman LP 2007 Signaling by estrogens. Journal of Cellular Physiology 213 610-617.

Cvoro A, Tzagarakis-Foster C, Tatomer D, Paruthiyil S, Fox MS \& Leitman DC 2006 Distinct roles of unliganded and liganded estrogen receptors in transcriptional repression. Molecular Cell 21 555-564.

DeNardo DG, Kim HT, Hilsenbeck S, Cuba V, Tsimelzon A \& Brown PH 2005 Global gene expression analysis of estrogen receptor transcription factor cross talk in breast cancer: identification of estrogen-induced/ activator protein-1-dependent genes. Molecular Endocrinology 19 362-378.

Eliassen AH \& Hankinson SE 2008 Endogenous hormone levels and risk of breast, endometrial and ovarian cancers: prospective studies. Advances in Experimental Medicine and Biology 630 148-165.

Foster JS, Henley DC, Ahamed S \& Wimalasena J 2001 Estrogens and cell-cycle regulation in breast cancer. Trends in Endocrinology and Metabolism 12 320-327.

Geisinger KR, Kute TE, Pettenati MJ, Welander CE, Dennard Y, Collins LA \& Berens ME 1989 Characterization of a human ovarian carcinoma cell line with estrogen and progesterone receptors. Cancer 63 280-288.

Gompel A \& Plu-Bureau G 2007 Ovarian cancer and hormone replacement therapy. Lancet 370 932-933.

Greenlee RT, Murray T, Bolden S \& Wingo PA 2000 Cancer statistics. CA A Cancer Journal for Clinicians $\mathbf{5}$ 7-33.

Han WD, Lou FD, Yu L, Han XP, Wang QS, Li N \& Zhou CX 2002 Bioinformatic analysis and subcellular distribution of LRP16 protein. Academic Journal of PLA Postgraduate Medical School 23 277-279.

Han WD, Mu YM, Lu XC, Xu ZM, Li XJ, Yu L, Song HJ, Li M, Lu JM, Zhao YL et al. 2003 Up-regulation of LRP16 mRNA by $17 \beta$-estradiol through activation of estrogen receptor $\alpha(E R \alpha)$, but not estrogen receptor $\beta(E R \beta)$, and promotes human breast cancer MCF-7 cell proliferation: a preliminary report. Endocrine-Related Cancer 10 217-224.

Han WD, Zhao YL, Meng YG, Zang L, Wu ZQ, Li Q, Si YL, Huang K, Ba JM, Morinaga $\mathrm{H}$ et al. 2007 Estrogenically regulated $\mathrm{ER} \alpha$ target gene LRP16 interacts with ER $\alpha$ and enhances the receptor's transcriptional activity. Endocrine-Related Cancer 14 741-753.

Han WD, Si YL, Zhao YL, Li Q, Wu ZQ, Hao HJ \& Song HJ 2008 GC-rich promoter elements maximally confer estrogen-induced transactivation of LRP16 gene through ER $\alpha / \mathrm{Sp} 1$ interaction in MCF-7 cells. Journal of Steroid Biochemistry and Molecular Biology 109 47-56.

Havrilesky LJ, McMahon CP, Lobenhofer EK, Whitaker R, Marks JR \& Berchuck A 2001 Relationship between expression of coactivators and corepressors of hormone receptors and resistance of ovarian cancers to growth regulation by steroid hormones. Journal of the Society for Gynecologic Investigation 8 104-113.

Heldring N, Pike A, Andersson S, Matthews J, Cheng G, Hartman J, Tujahue M, Ström A, Treuter E, Warner M et al. 2007 Estrogen receptors: how do they signal and what are their targets. Physiological Reviews $\mathbf{8 7}$ 905-931.

Hong CY, Suh JH, Kim K, Gong EY, Jeon SH, Ko M, Seong RH, Kwon HB \& Lee K 2005 Modulation of androgen receptor transactivation by the SWI3-related gene product (SRG3) in multiple ways. Molecular and Cellular Biology 12 4841-4152.

Hua W, Christianson T, Rougeot C, Rochefort H \& Clinton GM 1995 SKOV3 ovarian carcinoma cells have functional estrogen receptor but are growth-resistant to estrogen and antiestrogens. Journal of Steroid Biochemistry and Molecular Biology 55 279-289.

Langdon SP, Hawkes MM, Lawrie SS, Hawkins RA, Resdale AL, Crew AJ, Miller WR \& Smyth JF 1990 Oestrogen receptor expression and the effects of oestrogen and tamoxifen on the growth of human ovarian carcinoma cell lines. British Journal of Cancer 62 213-216.

Langdon SP, Crew AJ, Ritchie AA, Muir M, Wakeling A, Smyth JF \& Miller WR 1994a Growth inhibition of oestrogen receptor-positive human ovarian carcinoma by antiestrogens in vitro and in a xenograft model. European Journal of Cancer 30A 682-686.

Langdon SP, Hirst GL, Miller EP, Hawkins RA, Tesdale AL, Smyth JF \& Miller WR $1994 b$ The regulation of growth and protein expression by estrogen in vitro: a study of 8 human ovarian carcinoma cell lines. Journal of Steroid Biochemistry and Molecular Biology 50 131-135.

Lauritsen KJ, List HJ, Reiter R, Wellstein A \& Riegel AT 2002 A role for TGF-beta in estrogen and retinoid mediated regulation of the nuclear receptor coactivator AIB1 in MCF-7 breast cancer cells. Oncogene 21 $7147-7155$.

Liao DX, Han WD, Zhao YL, Pu YD, Mu YM, Luo CH \& Li XH 2006 The expression and clinical significance of LRP16 gene in human breast cancer. Ai Zheng 25 866-870.

McDonnell DP \& Norris JD 2002 Connections and regulation of the human estrogen receptor. Science 296 1642-1644.

Meng YG, Han WD, Zhao YL, Huang K, Si YL, Wu ZQ \& Mu YM 2007 Induction of LRP16 gene by estrogen promotes the invasive growth of Ishikawa human endometrial cancer cells through down-regulation of E-cadherin. Cell Research 17 869-880.

Mercier I, Colombo F, Mader S \& Calderone A 2002 Ovarian hormones induce TGF-beta(3) and fibronectin mRNAs but exhibit a disparate action on cardiac fibroblast proliferation. Cardiovascular Research $\mathbf{5 3}$ $728-739$.

Norris JD, Fan D, Stallcup MR \& McDonnell DP 1998 Enhancement of estrogen receptor transcriptional activity by the coactivator GRIP-1 highlights the role of activation function 2 in determining estrogen receptor pharmacology. Journal of Biological Chemistry 273 6679-6688.

O'Donnell AJM, Macleod KG, Burns DJ, Smyth JF \& Langdon SP 2005 Estrogen receptor- $\alpha$ mediates gene changes and growth response in ovarian cancer cells exposed to estrogen. Endocrine-Related Cancer 12 851-866.

Oesterreich S, Deng W, Jiang S, Cui X, Ivanova M, Schiff R, Kang K, Hadsell DL, Behrens J \& Lee AV 2003 Estrogen-mediated downregulation of E-cadherin in breast cancer cells. Cancer Research 63 5203-5208.

Pai JK, Pischon T, Ma J, Manson JE, Hankinson SE, Joshipura K, Curhan GC, Rifai N, Cannuscio CC, Stampfer MJ et al. 2004 Inflammatory markers and the risk of coronary heart disease in men and women. New England Journal of Medicine 351 2599-2610.

Pfeilschifter J, Koditz R, Pfohl M \& Schatz H 2002 Changes in proinflammatory cytokine activity after menopause. Endocrine Reviews $\mathbf{2 3}$ 90-119.

Prall OW, Rogan EM, Musgrove EA, Watts CK \& Sutherland RL 1998 c-Myc or Cyclin D1 mimics estrogen effects on Cyclin E-Cdk2 activation and cell cycle reentry. Molecular and Cellular Biology 18 4499-4508. 
Riman T, Dickman PW, Nilsson S, Correia N, Nordlinder H, Magnusson CM, Weiderpass E \& Persson IR 2002 Hormone replacement therapy and the risk of invasive epithelial ovarian cancer in Swedish women. Journal of the National Cancer Institute 94 497-504.

Rodrigez C, Patel AV, Calle EE, Jacob EJ \& Thun MJ 2001 Estrogen replacement therapy and ovarian cancer mortality in a large prospective study of US women. Journal of the American Medical Association 285 1460-1465.

Safe S 2001 Transcriptional activation of genes by $17 \beta$-estrodial through estrogen receptor-Sp1 interactions. Vitamins and Hormones 62 231-252.

Sampath D, Winneker RC \& Zhang Z 2001 Cyr61, a member of the CCN family, is required for MCF-7 cell proliferation: regulation by 17betaestradiol and overexpression in human breast cancer. Endocrinology 142 2540-2548.

Shang YF 2006 Molecular mechanisms of oestrogen and SERMs in endometrial carcinogenesis. Nature Reviews. Cancer 6 360-368.

Shang Y \& Brown M 2002 Molecular determinants for the tissue specifity of SERMs. Science 295 2465-2468.

Shi Y, Downes M, Xie W, Kao HY, Ordentlich P, Tsai CC, Hon M \& Evans RM 2001 Sharp, an inducible cofactor that integrates nuclear receptor repression and activation. Genes and Development 15 1140-1151.

Slotman BJ \& Rao BR 1988 Ovarian cancer: etiology, diagnosis, prognosis, surgery, radiotherapy, chemotherapy and endocrine therapy. Anticancer Research 8 417-434.

Smyth JF, Gourley C, Walker G, MacKean MJ, Stevenson A, William AR, Nafussi AA, Rye T, Rye R, Stewart M et al. 2007 Antiestrogen therapy is active in selected ovarian cancer cases: the use of letrozole in estrogen receptor-positive patients. Clinical Cancer Research 13 3617-3622.

Stossi F, Likhite VS, Katzenellenbogen JA \& Katzenellenbogen BS 2006 Estrogen-occupied estrogen receptor represses cyclin G2 gene expression and recruits a repressor complex at the cyclin G2 promoter. Journal of Biological Chemistry 281 16272-16278.

Syed FA, Modder UIL, Fraser DG, Spelsberg TC, Rosen CJ, Krust A, Chambon P, Jameson JL \& Khosla S 2005 Skeletal effects of estrogen are mediated by opposing actions of classical and non-classical estrogen receptor pathways. Journal of Bone and Mineral Research 20 1992-2001.
Syed FA, Fraser DG, Spelsberg TC, Rosen CJ, Krust A, Chambon P, Jameson JL \& Khosla S 2007 Effects of loss of classical estrogen response element signaling on bone in male mice. Endocrinology 148 1902-1910.

Wagner U, du Bios A, Pfisterer J, Huober J, Loibl S, Lück HJ, Sehouli J, Gropp M, Stähle A, Schmalfeldt B et al. 2007 Gefitinib in combination with tamoxifen in patients with ovarian cancer refractory or resistant to platinum-taxane based therapy - a phase II trial of the AGO Ovarian Cancer Study Group (AGO-OVAR 2.6). Gynecologic Oncology 105 132-137.

Woodward TL, Mienaltowski AS, Modi RR, Bennett JM \& Haslam SZ 2001 Fibronectin and the alpha(5)beta(1) integrin are under developmental and ovarian steroid regulation in the normal mouse mammary gland. Endocrinology 142 3214-3222.

Yager JD \& Davidson NE 2006 Estrogen carcinogenesis in breast cancer. New England Journal of Medicine 354 270-282.

Yang J, Zhao YL, Wu ZQ, Si YL, Meng YG, Fu XB, Mu YM \& Han WD 2009 The single-macro domain protein LRP16 is an essential cofactor of androgen receptor. Endocrine-Related Cancer 16 139-153.

Zhao YL, Han WD, Li Q, Mu YM, Lu XC, Yu L, Song HJ, Li X, Lu JM \& Pan CY 2005 Mechanisms of transcripitional regulation of LRP16 gene expression by $17 \beta$-estradiol in MCF-7 human breast cancer cells. Journal of Molecular Endocrinology 34 77-89.

Zhou B, Sun Q, Cong R, Gu H, Tang N, Yang L \& Wang B 2008 Hormone replacement therapy and ovarian cancer risk: a meta-analysis. Gynecologic Oncology 108 641-651.

Zubairy S \& Oesterreich S 2005 Estrogen-repressed genes-key mediators of estrogen action? Breast Cancer Research 7 163-164.

Zwijsen RM, Wientjens E, Klompmaker R, van der Sman J, Bernards R \& Michalides RJ 1997 CDK-independent activation of estrogen receptor by cyclin D1. Cell 88 405-415.

Received in final form 22 April 2009

Accepted 29 April 2009

Made available online as an Accepted Preprint 29 April 2009 